\title{
MURALISMO: ARTE, CULTURA E PÓS-HUMANISMO
}

\section{MURALISM: ART, CULTURE AND POSTHUMANISM}

DOI: http://dx.doi.org/10.5965/1984317815022019050

Tiago Scalvenzi Sául Instituto Federal do Paraná

tiago.saul@ifpr.edu.br

Magda Salete Vicini Instituto Federal do Paraná magda.vicini@ifpr.edu.br

Neuza de Fátima Fonseca Instituto Federal do Paraná neuza.fonseca@ifpr.edu.br

Douglgas Colombelli Parra Sanches Instituto Federal do Paraná douglas.sanches@ifpr.edu.br

Luiz Ney Todero Instituto Federal do Paraná luiz.todero@ifpr.edu.br

Francesca Ferrando Universidade de Nova lorque francesca.ferrando@gmail.com

\section{RESUMO}

Este projeto de pesquisa e extensão teve como objetivo pensar a arte do mural como representação de culturas e etnias formadoras do município de Palmas (PR), a partir da concepção do pós-humanismo em sua vertente crítica e o conceito de "inclusivismo situado" proposto pela filósofa italiana Francesca Ferrando; questionando o conceito de cultura, visando uma proposta de criação e execução de um mural. Apresenta-se um breve histórico da formação étnica indígena da Terra Indígena Kaingang e quilombola das Comunidades Quilombola Maria Adelaide Trindade Batista, Castorina Maria da Conceição e Tobias Ferreira, cujas culturas possuem pouca referência e visibilidade entre os habitantes que integram e participam do cotidiano e da história deste município, assim como sírio-libaneses e japoneses, fato que motivou essa pesquisa. Conceitua-se a arte do mural como proposta de produção artística com viés social, utilizando a metodologia pós-humana; a metodologia de pesquisa qualitativa, bibliográfica exploratória e aplicada com a produção de pintura mural; e ainda, entrevistas pós produção artística aos representantes das etnias que compõem o mural. O mural elaborado a partir desta pesquisa está instalado no IFPR - Campus Palmas.

Palavras-chave: Arte. Muralismo. Cultura. Pós-humanismo.

\section{ABSTRACT}

This project of research and extension, had as objective to think the art of the mural as a representation of the culture and formative ethnicities of the municipality of Palmas (PR), from the conception of post-humanism in your critical aspect and "inclusiveness located" proposed by the Italian philosopher Francesca Ferrando; in order to propose some concept questions of culture. A brief history of the ethnic formation of the Kaingang Indigenous Land and Maria Adelaide Trindade Batista, Castorina Maria Conceição and Tobias Ferreira afro-descendants ethnic, whose cultures have little refer- 
ence and visibility among the inhabitants that integrate and participate in daily life and history of this municipality, as well as Syrian-Lebanese and Japanese, a fact that motivated this research. The art of the mural is conceptualized as a proposal of artistic production with a social art, using the post-human methodology; the methodology of qualitative, exploratory and applied research, and the production of mural painting; as well as interviews with the representatives of the ethnic groups that compose the mural. The mural elaborated from this research, is installed in IFPR - Campus Palmas.

Keywords: Art. Muralism. Culture. Posthumanism.

\section{INTRODUÇÃO}

Realizar pesquisa sobre cultura significa observar o contexto no qual se está inserido enquanto pesquisador, retrocedendo historicamente no sentido de fundamentar o olhar para os dias atuais. Nesse sentido, nos situamos no estado do Paraná, cidade de Palmas, no qual houve a colonização europeia, inserindo sua cultura sobre a cultura dos índios originais desse espaço geográfico, bem como de outras imigrações que nesta região se instalaram. Observase no processo de colonização do Brasil e do sul do país, o que Braidotti (2013, p.13) denomina de "visão de auto-engrandecimento" europeu que possui seus seguidores entre os imigrantes que vieram ao Brasil no final do século XIX e início do século XX. Essa percepção que salientamos aqui não pretende julgar ou penalizar, mas tornar consciente o que se tornou supremacia e poder diante de outro ser humano, sem as mesmas condições materiais, sociais, culturais, econômicas e políticas, e que se perpetuam até os dias atuais. Esta suposta supremacia instaurou-se nos processos de colonização no Brasil, e inclusive na cidade de Palmas (PR), como está descrito nas próximas páginas desse artigo. Por mais que a mão dos negros esteja e esteve fazendo parte do município, se faz necessário um reconhecimento de igualdade, de que os negros pertencem a este lugar, entre os habitantes ${ }^{1}$, no sentido de possibilitar visibilidade a esta etnia. Os habitantes das cidades colonizadas em nosso país concebem e afirmam que as terras pertenciam e pertencem aos indígenas, mas percebe-se um ocultamento cultural e social, a não ser em desfiles da semana da pátria ou eventos culturais escolares. Percebe-se também, em algumas cidades, que 
não há a arte pública ou menção social de que essas etnias ${ }^{2}$ fazem parte dos fatos históricos originais. Em se tratando da cidade de Palmas, a não ser em poucos livros, sites e artigos como é apresentado brevemente neste artigo. Essa não visibilidade de etnias minoritárias, ou seja, os habitantes da Terra Indígena Kaingang e dos quilombolas da Comunidade Maria Adelaide Trindade Batista, da Comunidade Castorina Maria da Conceição e da Comunidade Tobias Ferreira, motivou a realizar este projeto de pesquisa e extensão, de forma a integrá-los às outras etnias que habitam esta cidade. A saber: europeus, japoneses e sírio-libaneses.

Como coordenadora deste projeto, pretendeu-se continuar os estudos sobre a filosofia pós-humana, desenvolvida desde o ano de 2013. Segundo o filósofo alemão e professor da Universidade John Cabbot de Roma (Itália) Stefan Lorenz Sorgner (2014, p.8. Tradução nossa), o Pós-humano "está associado com a filosofia pós-moderna e continental, estudos de ciência e tecnologia, e os estudos pós-coloniais". Ainda, na leitura de Sorgner (2014, p. 8), “o póshumanismo rejeita os dualismos humanistas: natureza/cultura, homem/mulher, corpo/mente, entre outros". A partir de uma concepção de que a cultura e a arte são atributos inerentes ao "ser"3, propõe-se que a arte social venha contribuir com esta nova percepção de "sermos" na filosofia pós-humana, desenvolvendo a sensibilidade, a percepção do Outro/outro (HEGEL, 2008; DELEUZE apud GALLO, 2012), igual e diferente de mim (cultura e arte) e o trabalho interdisciplinar nas ciências humanas, como propõe a filósofa e pesquisadora da Universidade de Ultrecht, Rosi Braidotti (2013), que em seu livro "The Posthuman", sugere que as ciências humanas dentro das universidades sobreviverão se utilizarem algumas estratégias como a cartografia e a interdisciplinaridade.

2 O termo "etnia" compreende-se aqui neste artigo a partir de sua origem grega "ethnos", ou seja, povo, grupo de pessoas, de uma nação, cujos aspectos genéticos e fenotípicos são instituídos socialmente e organicamente como semelhantes, bem como grupos que possam trazer em comum aspectos culturais de todas as esferas da vivência comum, povos esses originários de espaços geográficos definidos também institucionalmente, como por exemplo: etnia indígena brasileira; etnia afro descendente brasileira, etnia europeia ocidental, etc.

3 Grifo nosso. 
Procurou-se desenvolver a pesquisa de forma coletiva: com cinco professores do curso de Artes Visuais, bolsistas PRADI (Programa de Apoio ao Desenvolvimento e Inovação - IFPR) e PIBIS (Programa Institucional de Apoio à Inclusão Social Pesquisa e Extensão Universitária).

A produção da pintura mural se caracteriza como uma poética de arte que possibilita, a partir dos seus primeiros fundamentos históricos, uma abordagem artístico-social que, entre outros aspectos, possibilita sua visualização a todos os níveis da população, uma vez que pode ser realizada em locais abertos e de fácil acesso público. Apresenta-se a técnica de pintura Mural como linguagem que pode desvelar o "estar permanente" da cultura como proposta de produção de conhecimento e prática artística, possibilitando agregar conhecimento e compreensão sobre a arte como forma de praticar, vivenciar e inserirse em sua própria cultura, sob uma perspectiva pós-humana. Na proposta da pesquisa, inserir todas as etnias em uma expressão pictórica, cujas imagens apresentem uma oposição ao euro-centrismo colonizador.

Inicialmente, neste artigo, conceitua-se a arte do mural em sua concepção histórica e contemporânea (ARGAN, 1992; BELL, 2008; VASCONCELLOS, 2005; CANCLINI, 1984), apresentando nas últimas páginas o resultado final da criação do mural "Etnias e culturas formadoras do município de Palmas", fundamentada nos pressupostos teóricos e, finalmente, apresentando as etnias formadoras de Palmas (PR), comunidade acadêmica e local uma pintura mural.

Propõe-se a apresentar os pontos conceituais fundamentais que este projeto de pesquisa e extensão pretendeu explorar, indagar e utilizar sobre o muralismo (ARGAN, 1992; BELL, 2008; VASCONCELLOS, 2005; CANCLINI, 1984), a metodologia pós-humana (BRAIDOTTI, 2013; FERRANDO, 2012; SANTAELLA, 2007), bem como sua metodologia na produção de conhecimento e sua filosofia. Seguindo posteriormente com reflexões sobre a forma pela qual se tem conceituado a cultura (HALL, 2005; SOUZA, 2009; KAJIBANGA, 2001; CERTEAU, 1995; CANCLINI, 2008; ANJOS, 2005), a identidade e a contextualização das etnias indígena e quilombola do município de Palmas (PRIORI, 
2012; MOTA, 1994; RODRIGUES, s/d; MACHADO, 2015), no estado do Paraná, embora também façam parte as etnias: europeias, japonesa e síriolibanesa. Finalizando com as reflexões para a produção do Mural "Etnias e Culturas formadoras do Município de Palmas".

\section{MURALISMO}

A arte mural, pode apresentar-se de diversas formas no decorrer da História da Arte, mas não se pretende desenvolver aqui uma linha do tempo identificando as diversas maneiras que o mural foi apresentado desde a préhistória, mas delimitando-a ao momento artístico mexicano. O objetivo, nesse artigo, é introduzir essa linguagem artística citando o muralismo mexicano e um breve panorama do mural na atualidade.

As manifestações do mural no México, segundo o historiador da arte italiano Gian Carlo Argan (1909-1992), (1992, p.491)

[...] são a alternativa de consagrar uma revolução que pretende retirar o domínio de herdeiros espanhóis, em relação aos nativos descendentes de astecas e maias no México, com o apoio de intelectuais e artistas, com cunho ideológico claro, enaltecendo a cultura deste país, sua arte popular e folclore do período colonial.

O professor de história da Universidade de São Paulo (USP), Vasconcellos (2005, p.287) em artigo que aborda as representações das lutas de independência do México, estuda a relação do imaginário da arte em relação à independência, revelando a aproximação desses artistas com a história de seu povo.

A pintura mural mexicana teve início oficial nos anos 20 do século passado como "filha da Revolução de 1910», e foi a principal corrente estética da arte moderna no México, com grande repercussão por todo o continente americano e mesmo na Europa. Não que a Revolução por si só tenha gerado a arte mural, que já estava em estado embrionário, mas, com certeza, foi ela que permitiu sua emergência e esplendor em toda a sua magnitude. 
Outro historiador, artista, professor e pesquisador europeu, Julian Bell (2008), apresenta o movimento muralista por um viés político a partir da produção de Diego Rivera, escrevendo que esse artista, após estudos na Europa, voltou para o México para desenvolver murais como "adorno de edifícios públicos", e suas produções excluíam o pensar intelectualizado, aproximando-se das causas do povo (2008, p.401).

É importante destacar nessas concepções teóricas acima escritas, sobre o muralismo na leitura dos autores europeus, a ausência de reflexões sobre o estilo pictórico dos artistas, sua qualidade ou uma análise sobre a forma pelo qual esses murais são elaborados. Percebe-se, assim, um tratamento diferenciado, lembrando as palavras "folclore e decorativa" dos autores Argan e Bell em suas análises, em contraposição às obras de arte de artistas europeus. Essa ausência de uma análise formal sobre as obras de artistas fora do circuito europeu vem ser uma das premissas para se pensar o pós-humanismo, ou seja, o euro-centrismo humanista, como será visto no decorrer deste artigo.

Ao buscar mais referências bibliográficas sobre o muralismo na internet, sendo em sites de pesquisa científica, busca de livros e $\operatorname{artigos}^{4}$, percebe-se que em sua maioria, os artigos e pesquisas sobre o mural referem-se a aspectos sociais e políticos da produção muralista na América Latina, o que se torna pertinente pelo fato de o muralismo ter sido uma linguagem da arte cuja origem se deu de forma revolucionária, identitária.

Faz-se necessário lembrar também que a linguagem mural teve uma força social e reveladora de conflito político e religioso na Europa, na Irlanda do Norte, quando protestantes e católicos ou, na linguagem irlandesa, os "lealistas" (protestantes) e os "republicanos" (católicos) comunicavam-se a partir dos murais realizados em muros, paredes de casas e empresas. Segundo Gerry Adams, presidente dos "Sinn Féin" (Católicos-Republicanos) no Documentário

\footnotetext{
4 Busca no Períodicos Capes: "El muralismo mexicano desde un filtro filosófico. La relación entre la estética marxista y el muralismo”, de Maricela González. A Contracorriente: Revista de Historia Social y Literatura en América Latina, 2013, Vol.11(1), pp.395-401; Cecilia Belej, Historia y espacio, 2014, Issue Gubernamentalidad neoliberal, muralismo y resistencia política en el barrio de La Boca. Blasco, Luis María Question, 2015, Vol.1(48), pp.298-307; entre outros.
} 
"Arte do Conflito: murais na Irlanda" (2012) de Valeri Vaughn, produtor americano, eles utilizaram a arte na linguagem do mural como forma de expressar a violência e repressão, pois eram censurados pela televisão, os jornais de ambos grupos eram invadidos entre si e por policiais, e o mural funcionava como uma forma de comunicação com o mundo e entre eles próprios.

Pensando o mural na contemporaneidade, no ano de 2010, a Fundação Miró de Barcelona (Espanha) protagonizou a exposição "Murals: Práctiques Murals Contemporánies"5 (Catálogo da Exposição, 2010), trazendo uma eclética produção contemporânea de murais de artistas dos continentes Africano, Europeu, Asiático e Americano. Da África, a Cooperativa Feminina de Djajibiné Gandega "Djida", que é uma etnia subsaariana da Mauritânia (África), revela que a pintura mural doméstica mantém vivas as antigas tradições sociais e culturais, nas quais as mulheres se encarregam desta prática de seus ancestrais soninke. Trata-se de uma atividade coletiva desse povo, dedicada aos recémcasados que iniciam uma nova família. Para outro expositor dessa mostra, o artista alemão Götz (Catálogo da Exposição, 2010, p.135), começar a pintar nas paredes foi uma escolha para "[...] criar uma conexão entre a pintura e o espaço, criando um espaço ilusório e abstrato", e pretendia criar uma relação entre a parede e a arquitetura, como parte de uma história do passado, criando algo novo.

A pintura mural não se torna exclusiva de paredes externas, não se reduz mais a questões explicitamente ideológicas e culturais, como se analisa no Catálogo da Exposição da Fundação Miró (2010), há artistas que pretendem discutir somente as questões formais e estéticas nos murais atuais, como se vê também nas pinturas em grafite.

Entende-se a leitura dos autores europeus Argan e Bell, como uma breve análise sobre o muralismo mexicano, sem aprofundar nas questões de

5Artistas: Cooperativa Feminina de Djajibiné Gandega (Mauritânia) da África OcidentalLothar Götz (Alemanha), Scope One (Singapura), Utr Crew (Bósnia Herzegovínia), Jerónimo Hagerman (México), Sakarin Krue-on (Tailândia), Brian Rea (Estados Unidos), Nuria + Eltono (Espanha e França), Paul Morrison (Grã-Bretanha), Ludovica Gioscia (Itália) e Jacob Dahlgren (Suécia). 
conteúdo e forma desses artistas para a História da Arte. Essa observação se torna relevante quando se visualiza nesse projeto a criação e execução de um mural, considerando tanto os aspectos sociais e culturais envolvidos na produção, no caso, os habitantes Kaingang e Quilombolas de Palmas, como o conteúdo e a composição formal para apresentar e ou representar as etnias formadoras da cidade de Palmas. Para pensar o muralismo a partir de um cunho identitário e cultural, como se representa nesse projeto, é pertinente levar em consideração um aspecto relevante da sociologia da arte. Por esse caminho, o antropólogo argentino Néstor Canclini (1984, p.22) define que,

[...] ao se trabalhar a arte sociologicamente, pode-se correr o risco de separar o conteúdo da forma, na obra artística, como se apenas os fatos externos do conteúdo definissem a obra, reduzindo a obra a ideias. Afinal, são diversas as formas simbólicas, sígnicas, compositivas que se apresentam nas diferentes linguagens artísticas.

O autor ressalta uma preocupação que o grupo de pesquisadores possuía em relação aos símbolos e signos pelos quais poderiam ser expressos no mural e que seriam relevantes para cada etnia ali representada, uma vez que a arte se detém a alguns critérios formais para executar uma pintura. Ou seja, apresentar imagens sobre as culturas indígenas e quilombolas, bem como europeia, japonesa e sírio-libanesa, sem tornar relevantes os aspectos formais compositivos que constituíram a pintura.

\section{PÓS-HUMANISMO E SUA METODOLOGIA}

Falar sobre pós-humanismo requer uma explanação epistemológica de vertentes existentes neste movimento cultural e filosófico (SORGNER; GRIMM, 2012, p.12). O termo pós-humanismo foi apresentado pela primeira vez pelo professor e escritor da Universidade de Princenton (EUA), Ihab Hassan, em seu artigo "Prometheus as performer: toward a posthumanist culture?" (1977). Nesse artigo, Hassan, apresentado por Franssen (2014), justifica o uso da palavra pós-humanismo, anunciando que "os quinhentos anos de humanismo 
podem estar chegando ao fim", e que este "desesperadamente" vai se chamar pós-humanismo (FRANSSEN apud SORGNER; RANISCH, 2014, p.74. Tradução nossa).

Para a professora da Universidade de Amsterdam Trijsje Franssen (apud SORGNER; RANISCH, 2014, p. 74. Tradução nossa), Hassan apresenta seu conceito a partir do mito de Prometeu, representando o espelho da ambiguidade humana, como ladrão e herói, como define Hassan "Prometheus é ele mesmo a figura de uma consciência falha lutando para superar [...] divisões [...]". Com relação ao pós-humanismo em si, o aspecto mais relevante das preocupações dialéticas deste mito refere-se (Idem, p.74. Tradução nossa):

Imaginação e Ciência, Mito e Tecnologia, Terra e Céu. Uma vez que ele retira o conhecimento dos deuses e divide com os humanos - fica "entre", compartilha, dissolve-se a divisão humanista: homem/máquina, subjetivo/objetivo, ciência/cultura, e o antropocentrismo.

Há que se considerar que uma das primeiras definições sobre o póshumanismo aborda a relação do ser humano com as novas tecnologias tanto no sentido das próteses que se adaptam ao corpo humano, a produção de seres com inteligência além da capacidade humana, os robôs, como também no sentido de melhoria genética e produção de sentido, e, ainda, os significados que essas tecnologias aportam na subjetividade humana, como apresenta Lucia Santaella, pesquisadora da PUC São Paulo (SANTAELLA, 2003). Já o professor da Faculdade de Comunicação Social da PUC (RS), Rüdiger (2007, $\mathrm{s} / \mathrm{p}$ ), acredita que os movimentos pós-humanos podem ser prenúncios de transformações filosóficas de nosso momento atual, afinal, afirma o filósofo "figuras como Kevin Warwick, Wendy Carlos, Stephen Hawkins" ${ }^{6}$ e outros são prova de que os ciborgues não são apenas personagens ficcionais, mas entidades que poderão se tornar cotidianas".

6 Kevin Warick (1954): Cientísta inglês, Professor da Universidade de Reading (Inglaterra) realiza pesquisa sobre interfaces neurais; Wendy Carlos (1939): compositora e pesquisadora de design de som no campo da música eletrônica; Stephen Hawkins (1941-2018): físico e cosmólogo britânico. 
Atualmente, esse termo se expande, como para a professora e filósofa italiana da Universidade de Nova lorque Francesca Ferrando (2013), afirmando que o sentido do pós-humanismo pretende ir além desta relação entre seres humanos e tecnologias, propondo uma forma de rever posicionamentos ocidentais e fragmentários que foram as práticas do humanismo. Para Ferrando, o pós-humanismo refere-se a sustentabilidade humana, incluindo os direitos humanos, sem a polarização simplista, à imanência transcendental, sem dualismos como por exemplo "sujeito/objeto, eu/outro, masculino/feminino, humano/ animal, alien/robô" (2012, p.10-11.Tradução nossa).

Caminhando neste mesmo sentido, a Professora e filósofa da Universidade de Ultrecht (Holanda), Rosi Braidotti (2013, p. 12), afirma que seu interesse no pós-humanismo é devido ao fato de estar frustrada com o humano, demasiado humano, que limitam nossas possibilidades intensas e criativas a nível individual e coletivo. Braidotti (2013, p.38.Tradução nossa) aponta para a existência de três vertentes no pós-humanismo:

[...] a primeira surge da filosofia moral e desenvolve uma forma reativa de pós-humanismo; a segunda, provém dos estudos da ciência e tecnologias com uma forma analítica de pós-humanismo; e a terceira, vem de minha própria tradição anti-humanista pela subjetividade que propõe o pós-humanismo crítico".

Nesta proposta de pesquisa e extensão, optou-se pela terceira vertente pós-humanista, o pós-humanismo crítico, que se apresenta relacional, múltiplo em seu pertencimento (BRAIDOTTI, 2013, p.49, Tradução nossa):

[...] propõe o sujeito no âmbito de uma eco-filosofia de múltiplos pertencimentos, como um sujeito relacional constituído na e pela multiplicidade, isto quer dizer, um sujeito que atua entre diferenças e é também internamente diferenciado, mas ainda integrado e responsável.

Seguindo o pensamento pós-humano, a filósofa Ferrando (2012, p. 10-12. Tradução nossa), propõe uma metodologia pós-humana que sugere evitar o essencialismo hegemônico e o resistente. Ferrando (2012, p.12. Tradução nossa), ao conceituar o primeiro, refere-se "ao hábito generalizado de apenas 
referir-se a pensadores, artistas ou teóricos que pertencem a uma hegemonia cultural" (FERRANDO, 2013, p. 13. Tradução nossa). Assim, um texto pós-humano deve ser escrito por uma diversidade cultural de autores, evitando a tradicional hegemonia europeia ou americana. E o essencialismo resistente se apresenta como uma reação ao discurso intelectual hegemônico, para dar espaço a vozes que em determinado caso não teriam voz nenhuma, mas também, produziram muitas vezes relatos essencialistas e fragmentários, isto é, somente para mulheres ou negros (FERRANDO, 2012, p.15. Tradução nossa).

A noção de pós-humanismo que foi desenvolvida nesta pesquisa e projeto de extensão aplicou-se à sua metodologia, uma vez que este movimento está em crescente averiguação e especulação de seus próprios conceitos e processos de compreensão. Opta-se por essa metodologia pelo sentido de aproximar-se dos estudos do pós-colonialismo envolvendo cultura e identidade, nesse caso específico da elaboração do mural, a supremacia europeia em relação às etnias Kaingang e Quilombolas de Palmas. Em seu profundo pensamento sobre o sujeito pós-humano, Braidotti (2013, p.49. Tradução nossa) propõe uma recomposição do humano, mas um vínculo afirmativo que localiza o sujeito no fluxo de relações com múltiplos outros. É nesse sentido do póshumanismo crítico que esta pesquisa se fundamentou. Na perspectiva de evidenciar as diferentes etnias formadoras do município de Palmas (PR), reconhecendo e expressando o olhar múltiplo entre os seres humanos, meio ambiente natural e científico no qual se está inserido como pesquisadores e artistas autores do mural artístico que está exposto no Campus do Instituto Federal desta cidade.

Nesse sentido, torna-se pertinente ouvir as vozes de outras culturas, em sentido global e local. Dessa forma, encontra-se sonoridade no município de Palmas (PR), os grupos isolados, indígenas e quilombolas, que convivem com o espaço dos europeus, sírio-libaneses e japoneses, mantendo-se protegidos como forma de persistência e defesa de seus valores, sua cultura e suas terras. O pós-humano pretende desconstruir o humano, no sentido de revisitar a teoria do especismo, que pode ser definido como "qualquer forma de discrimi- 
nação praticada pelos seres humanos contra outras espécies. [...] racismo ou o sexismo, o especismo é uma forma de preconceito que se baseia em aparências externas, físicas etc." (SINGER, 1998, p. 25-92 apud BURGGER, 2009), ou seja, o privilégio de alguns em detrimentos de outros: principalmente o privilégio do ser humano diante de todas as outras espécies. Segundo Ferrando (2013), o termo pós-humano é rizomático, permite diversas definições dentro do mesmo movimento.

Ao vislumbrar-se uma desocultação de grupos humanos de diferentes etnias e culturas na formação da cidade de Palmas, Paraná, como uma crítica ao humanismo que aceita essas ausências culturais, acredita-se que a metodologia pós-humana proporcionou uma prática e uma metodologia que nos auxiliaram nos propósitos existenciais e filosóficos desta visão artística-cultural. E, nesse sentido, o conceito de "inclusivismo situado", abordado no livro de Ferrando (2013), foi amplamente adotado neste projeto. Assim, os pesquisadores pretendiam realizar uma pintura mural, com objetivo de inclusão cultural e social das etnias indígena e quilombola, sem perder a noção de que essas, estão em um coletivo diverso, ou seja, de várias culturas vivendo em um mesmo espaço. Para refletir sobre esse aspecto inclusivo dessa proposta, acredita-se ser importante apresentar no decorrer do artigo, as falas dos representantes das etnias de Palmas presentes no dia da inauguração do mural em 22 de março de 2018, como por exemplo, do Sr. Hassegawa, Diretor de Cultura da Associação nipo-brasileira de Palmas: "Eu achei muito interessante, muito bem representado, começando pelo formato do símbolo do Paraná, a araucária, e também representando todas as etnias. É muito importante fazer lembrar a formação do município de Palmas".

Essas palavras do representante nipo-brasileiro estão relacionadas ao "inclusivismo situado" que significa a prática pós-humana da constante reformulação simbólica humana, que se propõe não resolver no coletivo a perspectiva individual, mas que a reconheça em um pluralismo situado e não disciplinável. O risco dessa prática seria uma universalização acrítica e exclusiva, que impossibilitaria este conceito (FERRANDO, 2013, s/p. Tradução nossa). Nesse 
sentido, vislumbraram-se as políticas públicas, leis, proposições, emendas, tratados, cartas que a comunidade nacional e internacional elabora no sentido de garantir os Direitos Humanos, direitos civis, direitos econômicos, direitos de conflitos, etc. Haveria possibilidade de pensar e agir pluralmente, respeitando a perspectiva individual? Braidotti (2013) preocupa-se com a possível visão superficial que poderia desembocar em um pan-humanismo, no qual se apresente uma aceitação ou um pluralismo hegemônico de fachada, sem conflitos, sem identidades.

$\mathrm{Na}$ perspectiva de comprovar a rara ou nenhuma visibilidade das etnias indígena e quilombola no meio social e cultural da cidade de Palmas, apresentam-se a seguir, nas imagens, alguns monumentos que expressam o agradecimento do poder público municipal de Palmas para com os denominados "colonizadores" ou "desbravadores" dessas terras brasileiras (Figuras 1, 2, 3, 4, 5, 6) localizados em espaços de boa visibilidade. E, no ano de 2015, foi inaugurado uma homenagem aos índios de Palmas no Parque da Gruta (Fig. 7), localizado no interior deste Parque, com menos visibilidade do que os monumentos anteriores.

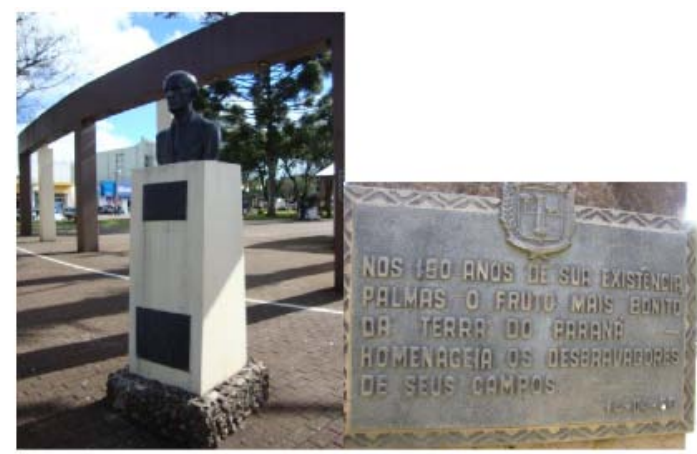

Figura 1 e 2 - Homenagem ao Dr. Bernardo Ribeiro Vianna - Arquivo Projeto Muralismo 


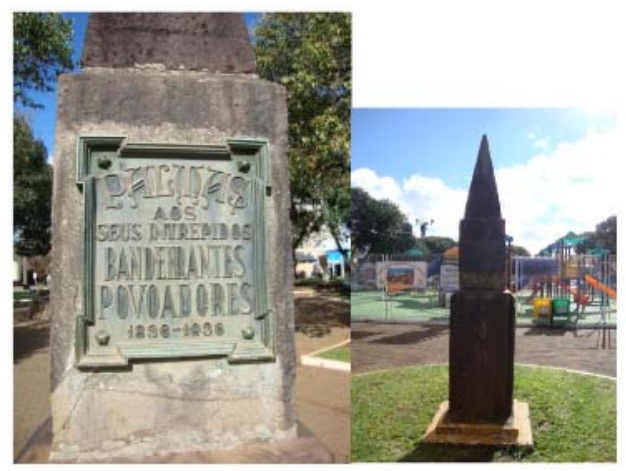

Figura 3 e 4 - Homenagem aos Bandeirantes - 1838-1936 - Arquivo Projeto Muralismo

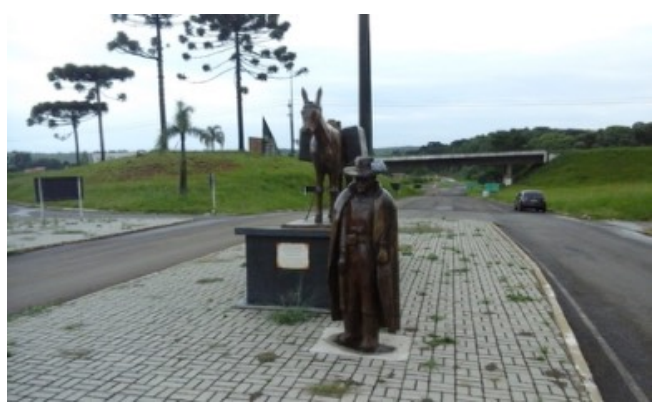

Figura 5 - Monumento aos tropeiros portugueses e paulistas - Trevo de acesso à cidade de Palmas - Arquivo Projeto Muralismo

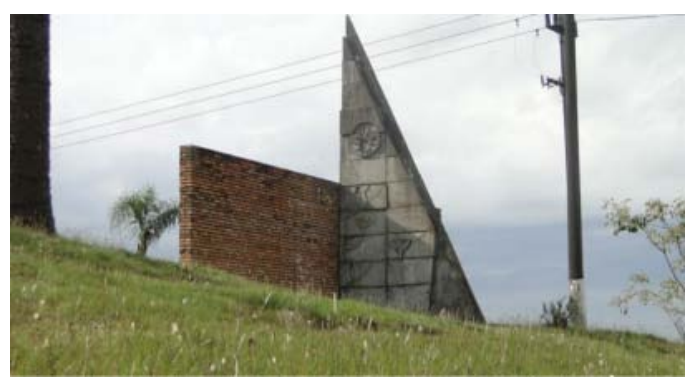

Figura 6 - Obra de Poty Lazarotto- Gravuras em concreto sobre a história de Palmas Arquivo Projeto Muralismo

E, no ano de 2015, foi inaugurado uma homenagem aos índios de Palmas no Parque da Gruta (Fig. 7), localizado no interior deste Parque, com menos visibilidade do que os monumentos anteriores. 


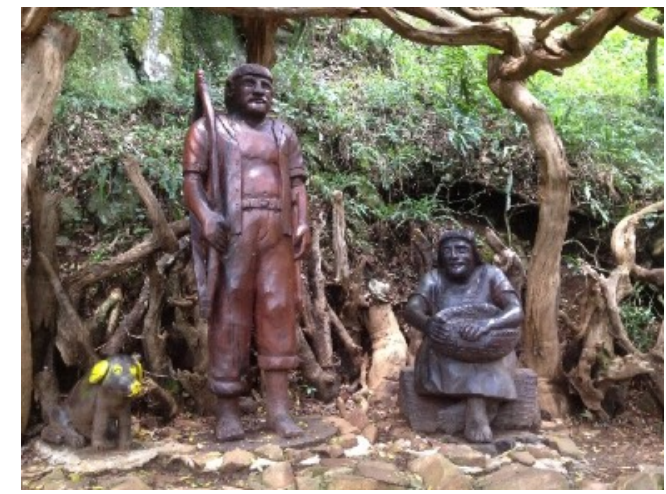

Fig.7 - Homenagens aos índios - Parque da Gruta (Palmas, PR) - 2015 Artista: Itacir Bortoloso - Arquivo: Projeto Muralismo

Como visualizado nas fotografias, a presença das etnias que fazem parte desta cidade possuem visibilidade parcial, ou seja, brancos tropeiros e brancos europeus, excluindo quilombolas, japoneses e sírio-libaneses.

\section{CULTURA}

A noção de cultura está geralmente implícita a de identidade do "ser humano" e o modo de se relacionar entre si e seus objetos contemporâneos, sua subjetividade, seu contexto, suas crenças, no sentido de que há um sujeito em determinado espaço que produz sinais e símbolos (CASSIRRER, 2005, p. 48-49) para se comunicar, para se proteger, para se alimentar e se expressar em diversas formas. Como pensar o conceito de cultura para o pós-humanismo? A relação da origem desta palavra, do grego, cultivo da terra pode sugerir o cultivo dos elementos da natureza - terra, células, vegetais, vida global, mente humana - entende-se não limitar-se ao "Humano". Mas a cultura está sempre interligada aos aspectos sociais, políticos, religiosos e históricos de cada país. Esse aspecto é importante em nosso contexto de pesquisa.

O Brasil, como os outros países ocidentais, no mundo moderno, viveu a onda das culturas nacionais que, segundo Hall (2005, p.49), trouxe um sentido de identidade, de pertencimento, como necessidade de fazer parte de algum lugar, a um grupo ou sociedade, e da mesma forma, cria-se um sistema de educação nacional. Para Souza (2009), professor de sociologia da Universidade 
Federal de Juiz de Fora - UFJF (MG), essa noção brasileira de moderno é similar (SOUZA, 2009, p.32):

[...] a noção moderna de nação é um processo, como todo processo social, de luta contra ideias rivais. [...] Uma nação se constitui apenas quando os nacionais se identificam efetivamente, em alguma medida significativa, como brasileiros e não mais, por exemplo, como gaúchos, paulistas ou pernambucanos.

Os habitantes brasileiros compactuam, então, hábitos, religião, linguagem, como aspectos solidários entre os seres e individualmente, para que exista uma identificação, criando o herói nacional, que fica imune à crítica (SOUZA, 2009, p.34).

Mas esta noção de homogeneidade moderna, de cultura e nação, está sendo fragmentada por uma "epistemologia do saber endógeno", como critica o sociólogo sul-africano Victor Kajibanga, quando questiona o sentido da "crioulidade" que caracterizou alguns autores como Gilberto Freyre e seu seguidor angolano Mário António Fernandes de Oliveira. Contrário aos pré-conceitos advindos de uma escritura e percepção europeias, o autor entende que é necessário distinguir que, mesmo na sociedade angolana, ocorreram 'enlaces de culturas', sendo o colonizado e o colonizador, recepção e doação de cultura (KAJIBANGA, 2001, p.152). Os colonizadores pretendem, em sua maioria, distinguirem-se do colonizado, evidenciando sempre sua cultura em detrimento da cultura daquele. Na transição do período moderno ao pós-moderno, percebe-se e pensa-se a cultura como uma concepção mais ampla e não fragmentada como outrora o pensamento moderno a mostrava. E, nesse sentido, o filósofo francês Certeau (1995), nos idos dos anos 1960, propõe que não há mais possibilidade de haver homogeneidade cultural, pois uma homogeneidade sempre implica em ausências: "A possibilidade de uma discussão repousa sobre pessoas excluídas e assuntos proibidos; é um fato, mas é preciso reconhecêlo" (CERTEAU, 1995, p.222). Para o antropólogo argentino Néstor Canclini (2008), ao escrever sobre cultura e sua complexidade vivida nos anos 1990 e sobre a inserção da América Latina na modernidade e pós-modernidade, a cul- 
tura apresenta-se como "híbrida", no sentido de processos de hibridação entre culturas. O autor justifica que utiliza este termo para também significar sincretismo, mestiçagem e outros, mas prefere hibridação "porque abrange diversas mesclas interculturais - não apenas raciais" (2008, p.19). Pensa-se, dessa forma, nessa proposta de pintura mural, o inclusivismo situado respeitando essas mesclas interculturais, ou seja, simbolismos individuais e coletivos. Esse conceito pode ser exemplificado no comentário que o então Cacique da Terra Indígena Kaingang (2017) sobre o mural realizado, o que vem significar a importância dos estudos pós-colonialistas para a filosofia pós-humana.

A gente se sente muito orgulhoso, muito honrado por ser representado e estar incluído no mural de nosso município. A gente se sente honrado... [...] Somos uma comunidade de aproximadamente mil pessoas e a gente nunca era lembrado. Hoje a gente está sendo lembrado e a gente agradece por isso. $^{7}$

Para ancorar este pensamento de amplitude cultural pós-humanista para a arte, abordar-se-á o termo transculturação e hibridismo que na visão de Moacir dos Anjos (2005, p.28) em seu livro "local/global: arte em trânsito", apresenta este termo como "proximidade entre formações culturais distintas". O autor revela (ANJOS, 2005, p.28-29):

Ao contrário dos conceitos de aculturação ou de mestiçagem, hibridismo sugere a impossibilidade da completa fusão entre componentes diferentes de uma elação, ainda que em situações de coexistência longa e próxima. [...] Por não estar inscrito na história social como o sincretismo, a crioulização e a diáspora, o termo hibridismo não invoca o reconhecimento imediato de que processos de transculturação são imersos em estruturas definidas de poder. Essa "neutralidade", entretanto, não o incompatibiliza com a ideia de que as ressignificações locais de códigos elaborados nas culturas hegemônicas, e a partir destas difundidos, são feitas, no âmbito da globalização, desde posições subordinadas. Mas ainda, permite-lhe abranger e destacar, sem ambiguidades - ao contrário desses outros termos -, o fato de que traduções simbólicas feitas a partir de posições periféricas não só articulam culturas distintas

\footnotetext{
${ }^{7}$ Resposta aos pesquisadores ao perguntarem ao Cacique se os indígenas Kaingang sentiam-se representados na pintura mural. Essa pergunta foi realizada no dia 22/03/2017, com todos os representantes das etnias que estavam presentes na inauguração do mural.
} 
como são incorporadas, com graus variados de legitimação, ao circuito mundial por onde informações trafegam, diversificando, expandido e "reindexando" aquele circuito, portanto como um espaço de traduções.

Moacir dos Anjos aproxima-se da reflexão de endogenia cultural aplicada pelo africano Kajibanga (2001), no sentido de reconhecer a interferência entre culturas. O autor perpassa as concepções de Stuart Hall e Homi K. Bhabha no horizonte de que "uma aproximação entre diferentes não vai se completar nunca, criando um entrelugar" (apud ANJOS, 2005, p.29). Essa percepção de aproximação entre diferentes, sem a dualidade humanista, a filosofia e o movimento cultural pós-humano pode estar relacionado com as palavras do Sr. Alcione, Presidente da Comunidade Quilombola Adelaide Maria Trindade Batista (2017), quando entrevistado no dia da inauguração do mural no IFPR Campus Palmas.

É uma satisfação, a felicidade nossa de hoje estarmos sendo representados nesse painel, nossa comunidade Quilombola de Palmas. As três comunidades, indígenas e toda essa miscigenação que hoje tem em Palmas e principalmente a visibilidade do nosso povo quilombola que está representado a partir da instituição IFPR. É com grande carinho que a gente recebe esse painel onde todos estão representados.

Apresentadas algumas concepções sobre cultura, e a fala de representantes de indígenas e quilombolas, a reflexão que este projeto provoca é no sentido de aproximar criticamente essas concepções ao espaço e aos fundamentos do pós-humanismo como "inclusivo situado" (Ferrando, 2013), pensando as relações possíveis entre a cultura e identidade local, européia neste caso específico e a desagregação e exclusão a que grupos étnico-culturais "minoritários" sempre se submeteram, como salienta o Professor Kaingang Claudecir Viri (2017), sobre a importância da pintura mural realizada.

Nós vemos assim, num primeiro momento: inclusão. Inclusão das culturas, trazer para o público a importância das culturas estarem presentes no município de Palmas, representando a etnia Kaingang. Me dá mais orgulho de ver que a sociedade, na verdade eles estão trazendo o conhecimento para os 
acadêmicos e para os demais que também estão buscando o conhecimento. Isso pra nós é muito importante, porque nós somos uma sociedade. Nós temos que trazer para o público as diferenças culturais, seja de qualquer etnia. A agente se sente com mais orgulho, a cultura se fortalece mais; o respeito pela cultura se expande e isso para nós é muito importante. $E$ a universidade dando o ponto inicial sobre a diversidade, isso quer dizer que jamais as culturas vão deixar de participar e de estar juntas no progresso da instituição.

Das hibridações culturais surgem novos símbolos, novas traduções das culturas que convivem neste mesmo espaço, mas sem a visibilidade e a aceitação de suas subjetividades e poderes de atuação em uma sociedade, como salienta o professor kaingang (2017), propondo a Universidade, o espaço da educação como o espaço para iniciar essa inclusão cultural.

\section{O CONTEXTO DO OBJETO DE PESQUISA: ORIGEM DA CIDADE DE PALMAS (PR)}

A cidade de Palmas (Paraná) possui 137 anos, e ao longo desses anos recebeu povos oriundos de diversas partes geográficas, sendo hoje uma mistura de muitas raças que foram chegando e se fixaram nessa terra, além de índios, os portugueses, alemães, italianos, poloneses, espanhóis e sírio-libaneses (RODRIGUES, s/d). Em sua história, assim como outros municípios do Paraná, esta cidade foi erguida sob o vazio demográfico. O povo coletor e caçador que aqui existiam foram varridos, caçados, empurrados à margem, tanto pelos brancos quanto pelos seus próprios irmãos. De acordo com Mota (1994, p.9) "[...] esses espaços, habitados por comunidades indígenas, passam a ser projetados como espaço vazio, improdutivo, pronto a ser ocupado pela economia nacional produtiva". O índio era visto como obstáculo que dificultava o desenvolvimento do progresso e seu consequente crescimento econômico, por isso, não se mediram esforços para superar esse incômodo.

Existem no Estado do Paraná aproximadamente 9015 Indígenas, habitando 85.264,30 hectares de terra. Essa área está distribuída em 17 porções 
de terras, abrigando as etnias Kaingang, Guarani e 6 remanescentes do povo Xetá. $A$ área indígena Kaingang da cidade de Palmas (PR) no passado era de 4.840 hectares (seg. memória oral, 2 mil alqueires), e conta atualmente com uma área territorial de 3.800 hectares, com população de 739 índios (Portal Kaingang, 2017).

O avanço econômico com a produção pastoril dessa região fez com que a população de Palmas crescesse. Porém, é importante salientar que, durante esse crescimento populacional, a presença do escravo foi marcante. De acordo com Machado (2015), estima-se que entre os anos de 1859 e 1888 a população de trabalhadores escravizados em Palmas foi de 235 negros. Dessa forma, entende-se que a população que ajudou a colonizar os campos de Palmas foram, inicialmente, os nativos que aqui já residiam, os colonos e os escravos africanos e negros.

Com base nisso, é importante salientar que "Assim como no restante do país, no Paraná também se formaram vários quilombos ou comunidades negras rurais, que existem até hoje" (PRIORI et al, 2012, p.49-50).

Muitos escravos negros conseguiram sua liberdade por meio de fugas e, como forma de manter essa nova realidade, deslocavam-se para locais de difícil acesso, como florestas. O resultado foi a criação de comunidades. Como coloca Priori et al (2012, p.49) sobre as comunidades, "O quilombo era um espaço de resgate e a firmação de identidade étnica e cultural. Nele, os quilombolas tinham liberdade para cultuar seus deuses e manter suas crenças e tradições".

Ao todo, no estado do Paraná, a Fundação Palmares, órgão do Ministério da Cultura, tem o registro de 34 comunidades quilombolas, sendo 3 na cidade Palmas. Os nomes dessas 3 comunidades são: Adelaide Maria Trindade Batista, Castorina Maria da Conceição e Tobias Ferreira.

\section{A COMPOSIÇÃO DO MURAL "ETNIAS E CULTURAS FORMADORAS DO MUNICÍPIO DE PALMAS (PR)}


Este estudo exploratório pretendeu falar sobre o pós-humanismo crítico, por meio do qual a arte pode traduzir ou evidenciar a presença multicultural de grupos étnicos em um espaço geográfico brasileiro, cujas identidades culturais, como um estar permanente entre coletividade ou individualidade, não possui um espaço que as represente como arte pública e social, bem como espaços de decisão. Utilizou-se, como fundamento, o conceito de "inclusivismo situado" como referenciado no item "Pós-humanismo e sua metodologia". Isso significa propor que a composição formal do mural em seu conteúdo, bem como em suas linhas, cores, tonalidades, figuras, texturas, ritmos, espaços e tempos, tivessem como objetivo a visibilidade de identidades culturais, sem a perspectiva de excluir a coletividade, a individualidade ou a particularidade dessas identidades.

O mural foi executado por três artistas professores do IFPR Palmas e um aluno bolsista da graduação. Deve-se considerar que o tempo para a criação e execução do mural foi delimitado ao espaço de quatro meses e a fundamentação teórica no período de seis meses, uma vez que este projeto foi contemplado com o Edital de Apoio do Programa de Apoio ao Desenvolvimento e Inovação do IFPR (PRADI) para ser executado em doze meses. Considera-se essa composição do mural já instalado no Campus do IFPR Palmas, como um estudo preliminar, que poderá ter novos estudos em murais futuros.

A concepção compositiva da pintura mural surgiu a partir de desenhos específicos sobre a figura humana das etnias, a pesquisa em desenhos sobre a vegetação, as formas orgânicas de silício, as formas orgânicas das moléculas de água e a forma do DNA. Após esses estudos, pensou-se a composição geral em sua dimensão e espacialidade do mural, que seria posteriormente passada para os outros dois professores artistas complementarem com suas criações. Também está evidenciada no mural a composição como "site specific", indicando o espaço educacional no qual seria exposto o mural - o Instituto Federal do Paraná - instituição educacional técnica e de graduação.

O fato de a pintura ter sido elaborada sem a característica fundadora do mural - a pintura em parede ou muro, - pode provocar muitas discussões téc- 
nicas ou estéticas, como defendeu, por exemplo, o pesquisador, artista e professor Mayer (1996, p.396), que aponta a parede como o suporte principal de um mural. Neste aspecto, a pesquisa precisou ser adaptada à realidade temporal e espacial a que se propunha executar naquele momento. Por questões de segurança, o mural foi pintado em peças de compensado $(1,10 \mathrm{~m} \times 2,20 \mathrm{~m})$ que posteriormente foram fixadas à parede do IFPR Palmas. No mural "Etnias formadoras do município de Palmas" foi utilizada a tinta acrílica para piso, pensando em sua durabilidade sobre a madeira e, para finalizar e proteger o suporte "compensado" foi aplicado verniz marítimo na parte posterior da chapa de compensado e sobre a pintura final.

A obra final foi desenvolvida em cores análogas no terceiro plano de fundo em tonalidades de azul e verde, pensando na relação entre terra e céu a natureza da cidade, a relação do índio e dos quilombolas com a terra, bem como a utilização desta pelos europeus e japoneses como produto econômico; e o azul do céu de Palmas com suas temperaturas baixas no inverno; assim como o azul que se referencia à água abundante nessa região. No segundo plano, em cores análogas buscando uma textura de metal, surgem as formas orgânicas de silício, direcionadas a pensar as tecnologias e a relação dessas com a pesquisa genética, a identidade local, à hibridização ou transculturação (Anjos, 2005) que ocorrem nas relações sociais; nesse plano ainda estão dispostas as moléculas de água e a cadeia de DNA que expressa essa hibridização oculta de múltiplas interferências entre os seres humanos e as culturas estabelecidas nessa cidade paranaense. Ainda neste segundo plano, expressase a vegetação dos butiazeiros, espécie de coqueiro ou ainda, também denominado "palmas", possível origem do nome desta cidade, como apontado no item sobre o contexto dessa região. Em primeiro plano, surgem as figuras humanas, também com uma paleta de cores análogas, as cores de pele e características faciais das etnias índios, negros, japoneses, europeus e sírio-libaneses, representados em três gerações: crianças/adolescentes, adultos/idosos, em três níveis dentro do mural. As crianças e adolescentes estão postas no primeiro nível, cujas bocas estão falando algo para o espectador da obra. Posterior- 
mente, os adultos e idosos, como fases de vidas que estão, estiveram presentes e são responsáveis pelo universo de cidadania deste espaço geográfico.

$\mathrm{Na}$ parte central, ainda em primeiro plano, estão os jovens do ensino médio/técnico e da graduação do IFPR, de diferentes etnias, diferentes idades e classes sociais, em resistência ao direito à educação pública em uma cidade cujo IDH está entre os mais baixos do Brasil. Continuando o primeiro plano, o caule da Araucária, árvore original dos Campos de Palmas e algumas regiões do sul do Brasil, que traz em sua textura, imagens de pássaros e máscaras que se fundem. Segundo o artista proponente desta composição, buscou mostrar os pássaros de uma natureza que em confrontos entre etnias locais, também produziu exclusão de muitos grupos humanos e favorecimento de outros.

No dia 22 de março de dois mil e dezessete, às dez horas da manhã, foi marcada a inauguração do mural "Etnias e Culturas Formadoras do Município de Palmas" (Figuras 8-9). A maioria das etnias se fizeram presentes na data da inauguração. Após o cerimonial de inauguração, foi o momento do descerramento da placa do mural, quando foram convidados todos os representantes das etnias presentes para este ato.

\section{CONCLUSÃO}

As conclusões e análises sobre esta produção de pesquisa e extensão foram sendo construídas ao longo da continuidade do projeto. Num primeiro momento, podemos considerar que alguns objetivos podem ter sido alcançados. Principalmente quanto à concepção metodológica pós-humana: a fundamentação teórica do projeto utilizou essa metodologia no sentido de utilizar-se de autores de diversas etnias e origens geográficas, como do Brasil, Argentina, Estados Unidos, Europa e África assim como procurando distanciar-se dos essencialismos hegemônico e radical (FERRANDO, 2012), propondo uma reflexão crítica e plural sobre a identidade e a inserção de etnias minoritárias em um contexto social. Propôs-se utilizar ainda o conceito de "inclusivismo 
situado", na visão de Ferrando (2012, s/p) "a prática pós-humana da constante reformulação simbólica humana, que se propõe não resolver no coletivo a perspectiva individual, mas que a reconheça em um pluralismo situado e não disciplinável". Essa possibilidade de refletir e atuar a partir do "inclusivismo situado", deu-se na composição do mural, no diálogo com as etnias formadoras do município de Palmas, nas entrevistas realizadas com os representantes dessas etnias e no ato de inauguração da obra, quando a maioria desses grupos étnicos se fez presente (Figura 8 e 9).

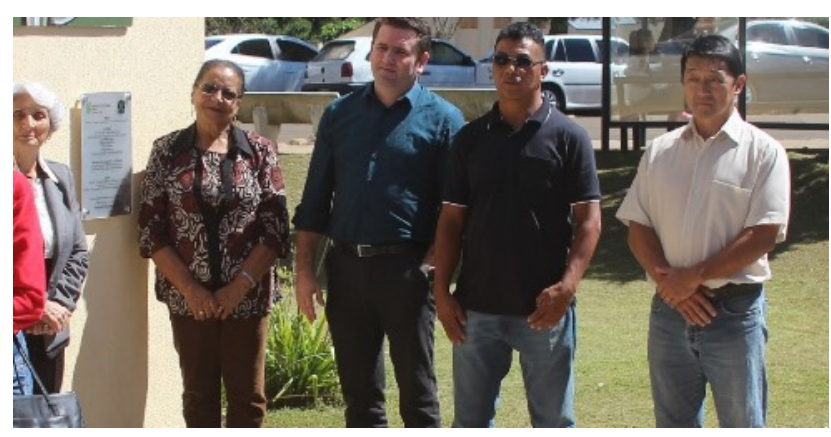

Figura 8 - Representantes das etnias: portuguesa, quilombola, indígena e japonesa Inauguração do Mural: 22/03/2017 - Arquivo Projeto Muralismo

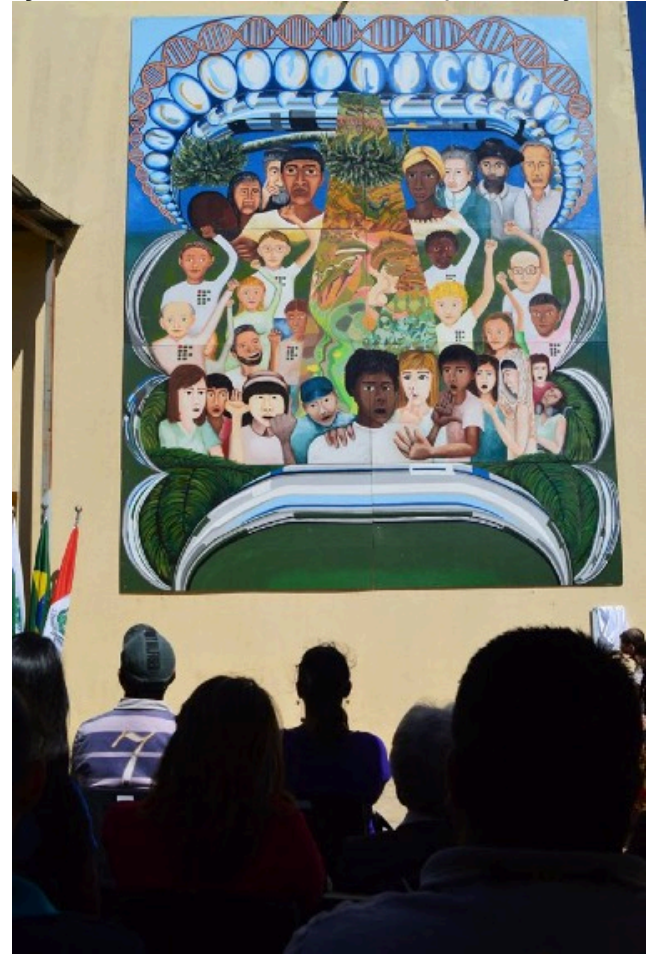

O mural foi fixado na entrada dos prédios do Instituto Federal do Paraná, Campus Palmas. Segundo os depoimentos das etnias presentes na inaugu- 
ração, eles consideraram importante "se verem" no mural, como inclusão, reconhecimento e respeito às etnias formadoras do município de Palmas, descrito nesta conclusão, conforme apresenta a Sra. Maria Arlete (2017), Matriarca da Comunidade Quilombola Adelaide Maria Trindade Batista:

\begin{abstract}
Primeiramente eu parabenizo os autores desse projeto ... e através desse projeto, desse painel é que vai se conhecer a verdadeira história de Palmas. Esse mural é profundo. Olhando para ele a gente descobre a história de Palmas que sempre foi invisível, principalmente para o negro e para o índio. E representa também todas as etnias de Palmas. [...] E estudando esse mural, a gente conhece a verdadeira história do Paraná, de Palmas e do Brasil. [...] Eu parabenizo a todos que se engajaram para dar mais visibilidade às culturas de Palmas.
\end{abstract}

Este projeto de pesquisa e extensão promoveu uma profunda reflexão, tanto para os integrantes pesquisadores ${ }^{8}$ e artistas, reflexão que resultou na produção deste artigo; como para os bolsistas, a compreensão do termo cultura; a comunidade acadêmica (professores, estudantes e técnicos) e a comunidade de Palmas. Algumas das reflexões provocadas aos professores da comunidade de nosso Campus pode ser percebida na análise realizada pela professora do curso de Pedagogia, Márcia Biezeck (2017).

Como professora, esse espaço traz a possibilidade de que cada pessoa que passar pelo mural possa se ver na obra. $E$ como cidadã, quilombola e kaingang nascida aqui em Palmas, essa visibilidade se torna evidente, porque o mural vem concretizar a construção, a abertura que o IFPR nos oferece enquanto docentes. [...] Eu vejo que esta obra nos representa realmente. Ela nos traz um sentimento de representatividade muito grande e me sinto orgulhosa de estar presente aqui.

O objetivo geral deste projeto foi alcançado com a execução do mural "etnias formadoras do município de Palmas", que está fixado no Instituto Federal de Palmas, bem como a proposta de integrar alunos do ensino médio e dos anos iniciais da graduação em Licenciatura em Artes Visuais, como a com-

8 As reflexões a partir da elaboração da pesquisa e das conclusões, levaram os pesquisadores em busca de mais conhecimento sobre o assunto, ao entrarem em programas de pós-doutorado, doutorado e mestrado. 
preensão do termo cultura e arte, a partir dos trabalhos apresentados pelos bolsistas; e ainda, a participação efetiva do bolsista Pradi, que auxiliou na pintura do mural. Acredita-se que as respostas que estão relatadas no decorrer da escritura deste artigo podem propor uma reflexão sobre o significado deste projeto para a comunidade acadêmica e palmense, como por exemplo, a resposta da Sra. Fávero, representante da Comunidade Ítalo-basileira (2017), que disse sentir-se agradecida pelo mural ter "mostrado o sofrimento que os italianos passaram quando vieram aqui no sul do Brasil", e que esse sofrimento "contribuiu para o desenvolvimento de Palmas".

O projeto "Muralismo: arte, cultura e pós-humanismo" teve continuidade no ano de 2017 com a proposta de apresentar o mural desenvolvido no IFPR, a partir de palestras em Colégios de Palmas, procurando motivar reflexões sobre cultura e identidade aos alunos do Ensino Médio.

\section{REFERÊNCIAS}

ANJOS, Moacir dos. Local/global: arte em trânsito. Rio de Janeiro: Jorge Zahar Editora, 2005.

ARGAN, Giulio Carlo. Arte moderna: do iluminismo aos movimentos contemporâneos. 2. ed. São Paulo: Companhia das Letras, 1992.

BELL, Julian. Uma nova história da arte. Trad. Roger Maioli. São Paulo: Martins Fontes, 2008.

BRAIDOTTI, Rosi. Diferença, Diversidade e Subjetividade Nômade. Tradução: Roberta Barbosa. labrys, estudos feministas. Número 1-2, julho/ dezembro 2002. Disponível em: http://www.historiacultural.mpbnet.com.br/feminismo/Diferenca Diversidade e Subjetividade Nomade.pdf. Acesso em: maio/2016.

BRAIDOTTI, Rosi. The Posthuman. Polity Press: Cambridge, EUA. Edição do Kindle, 2013.

BRUGGER, Paula. Nós e os outros animais: especismo, veganismo e educação ambiental. Linhas Críticas, Brasília, v. 15, n. 29, p. 197-214, jul./dez. 2009. ISSN 1981-0431. Disponível em: http://periodicos.unb.br/index.php/linhascriticas/article/view/ 6409. Acesso em: junho/2016.

CANCLINI, Néstor García. Culturas híbridas: estratégias para entrar e sair da modernidade; tradução Helóisa Pezza Cintrão, ana Regina Lessa. E. ed. E. reimpr. São Paulo Editora da Universidade de São Paulo, 2008. Cultrix, s/d.

A socialização da arte: teoria e prática na América Latina. São Paulo: editora 
CATÁLOGO DA EXPOSIÇÃO "PRÁCTIQUES MURAL CONTEMPORÁNIES". Fundação Juan Miró. Editora: Nova Era, S.A., Barcelona, 2010.

FERRANDO, Francesca. NB. Dall'11 al 14 Settembre 2013 si terrá la $5^{\circ}$ Conferenza Internazionale del Postumanesimo presso l'Universitá di Roma Tre, dal titolo: "The Posthuman: Differences, Embodiments, Performativity". Site Academia.edu. Disponível em: file:///D:/Users/User/Downloads/POSTUMANESIMO ALTERITA E DIFFERENZE.pdf.

Toward a posthumanist methodology: a statement. Disponível em: Acesso em outubro/2016.

GALLO, Silvio. Imagens do outro na filosofia: o desafio da diferença. ETD - Educ. Tem. Dig., Campinas, v.14, n.1, p.160-178, jan./jun. 2012 - ISSN 1676-2592. Disponível em: https://periodicos.sbu.unicamp.br/ojs/index.php/etd/article/view/1250. Acesso em: abril/2017.

HALL, Stuart. A identidade cultural na pós-modernidade. Tradução: Tomaz Tadeu da Silva, Guaracira Lopes Louro. 10 ed. Rio de janeiro: DP\&A, 2005.

https://www.academia.edu/1243762/TOWARDS A POSTHUMANIST METHODOLOGY A Statement. Acesso em fevereiro de 2014.

KAJIBANGA, Victor. Crise da racionalidade lusotropicalista e do paradigma da 'crioulidade' (O caso da antropossociologia de Angola). África: Revista do Centro de Estudos Africanos. USP, S. Paulo, 22-23: 141-156, 1999/2000/2001. Disponível em: www.revistas.usp.br/africa/article/viewFile/75259/78761. Acesso em: maio/2016.

MAYER, Ralph. Manual do Artista de Técnicas e Materiais. São Paulo. Martins Fontes, 1996.

MINAYO, Maria Cecília de Souza (org.). Pesquisa social: teoria, método e criatividade. 29. ed. Petrópolis, RJ: Vozes, 2010.

MOTA, Lúcio Tadeu. As Guerras dos Índios Kaingang. História Épica dos Índios Kaingang no Paraná (1769-1924) Editora da Universidade Estadual de Maringá - Maringá -PR, 1994.

Portal Kaingang. Disponível em: http://www.portalkaingang.org/index_palmas.htm. Acesso em: 22/010/2016.

PRIORI, Angelo; POMARI, Luciana Regina; AMÂNCIO, Silvia Maria; IPÓLITO, Veronica Karina. Comunidades quilombolas no Paraná In História do Paraná: séculos XIX e XX [online]. Maringá: Eduem, 2012, pp. 47-58. Disponível em: http://books.scielo.org/id/k4vrh/pdf/priori-9788576285878-05.pdf . Acesso em: 13 mai/2016.

RBJ Portal de Notícias. Disponível em: http://www.rbj.com.br/geral/patrimonio-culturalestado-reconhece-obra-de-poty-lazzarotto-em-palmas-2658.html. Acesso em 27/02/2017.

RODRIGUES, Eloyna Ribas. História. Disponível em: http://pmp.pr.gov.br/la/sobre.php. Acesso em: 20 de maio de 2016. 
SANTAELLA, Lucia. Culturas e artes do pós-humano: da cultura das mídias à cibercultura. São Paulo: Paulus, 2003.

SORGNER, Stefan Lorenz; RANISCH, Robert (Org.). Organizadores. Post- and Transhumanism: an introduction. Frankfurt am Main: Peter Lang, 2014.

SOUZA, Almir Antonio. A invasão das terras Kaingang nos campos de palmas. $O$ processo contra a liderança indígena Vitorino Condá (1839-44). Dossiê - Estudos sobre as sociedades Jê (Kaingang e Xokleng) no sul do Brasil. Revista Mediações, Londrina, V. 19 N. 2, p. 43-61, JUL./DEZ. 2014DOI: 10.5433/2176-6665.2014v19n2p43. Disponível em: http://www.uel.br/revistas/uel/index.php/mediacoes/article/view/20697. Acesso em setembro/2016.

SOUZA, Jessé. A ralé brasileira: quem é e como vive. Belo Horizonte: Editora UFMG, 2009.

VASCONCELLOS, Camilo de Mello. As representações das lutas de independência no México na ótica do muralismo: Diego Rivera e Juan O'Gorman. Revista de História, 01 December 2005, Vol.0(153), pp.283-304. Disponível em: www.revistas.usp.br/revhistoria/article/download/19013/21076. Acesso em: 30/04/2017.

\section{VIDEOS:}

ART of Conflict. 2012 - Documentário - 1h 13m. Este filme mostra o impacto, a função e o futuro dos murais na Irlanda do Norte, uma expressão dos violentos problemas sociais da Irlanda. Data de lançamento: 12 de outubro de 2012 (mundial). Direção: Valeri Vaughn. Produção: Vince Vaughn, Netflix. Disponível em: https://www.netflix.com/

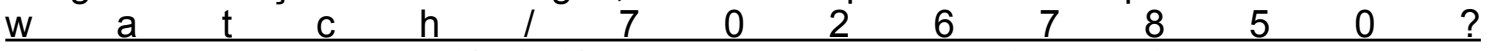

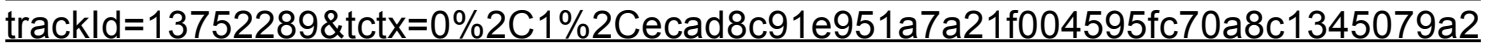
\%3Ac4a5b3e7b97a68b91de9093500d106dc1f890829. Acesso em 20/03/2017. 